\title{
Vital pulpa tedavisinde kullanılan kalsiyum silikat içerikli biyomateryallerin restoratif materyallere bağlanma dayanımının değerlendirilmesi ${ }^{*}$
}

\author{
Hüseyin Biçer(0000-0002-2354-4110 ${ }^{\alpha}$, Şule Bayrak(0000-0001-7023-2358) ${ }^{\alpha}$
}

Selcuk Dent J, 2019; 6: 271-279 (Doi: 10.15311/selcukdentj.434762)

Bașvuru Tarihi: 19 Haziran 2018 Yayına Kabul Tarihi: 24 Ocak 2019

\section{öz}

Vital pulpa tedavisinde kullanılan kalsiyum silikat içerikli biyomateryallerin restoratif materyallere bağlanma dayanımının değerlendirilmesi

Amaç: Bu çalışmanın amacı, vital pulpa tedavilerinde kullanılan kalsiyum silikat içerikli biyomateryallerin rezin modifiye cam iyonomer siman ve kompozit rezine makaslama bağlanma dayanımlarının karşılaştırmalı olarak değerlendirilmesidir.

Gereç ve Yöntemler: $4 \mathrm{~mm}$ çapında ve $2 \mathrm{~mm}$ derinlikte boşlukları bulunan 78 adet akrilik blok hazırlandı. Üretici firmaların talimatları doğrultusunda hazırlanan kalsiyum silikat içerikli biyomateryaller (ProRoot MTA, BioAggregate ve Biodentine) akrilik bloklardaki boşluklara yerleştirildi ve sertleşmeleri için önerilen sürelerde bekletildi. Biyomateryal örnekleri, rezin modifiye cam iyonomer siman ve kompozit rezin olarak 2 gruba ayrıldı. Adeziv ișlemlerin ardından biyomateryallerin üzerine $2 \mathrm{~mm}$ çapında ve $2 \mathrm{~mm}$ yüksekliğinde silindirik kalıplar yardımıyla restoratif materyaller uygulandı. Tüm örnekler 24 saat $37^{\circ} \mathrm{C}$ lik etüvde bekletildikten sonra makaslama bağlanma dayanım değerleri universal test cihazı kullanılarak ölçüldü. Elde edilen verilerin istatistiksel değerlendirilmesinde tek yönlü varyans analizi (One-way-ANOVA) ve Tukey testleri kullanıldı.

Bulgular: Tüm biyomateryallerde (ProRoot MTA, BioAggregate ve Biodentine) kompozit rezinin makaslama bağlanma dayanım değeri, rezin modifiye cam iyonomer simandan yüksek bulundu. Biyomateryaller karşılaştırıldığında ise, Biodentine'nin hem rezin modifiye cam iyonomer siman hem de kompozit rezine bağlanma dayanımının ProRoot MTA ve BioAggregate'den anlamlı olarak yüksek olduğu saptandı $(p<0.05)$.

Sonuç: : Sonuç olarak vital pulpa tedavilerinde kullanılan kalsiyum silikat içerikli biyomateryallerin üzerine restoratif materyal olarak kompozit rezin tercih edilebilir. Ayrıca Biodentine, hem bağlanma dayanımı açısından daha iyi değerler sergilemesi, hem de sertleşme süresinin daha kısa olması, manipülasyonunun daha kolay olması ve daha ucuz olması nedeniyle MTA ve BioAggregate'e iyi bir alternatif olabilir.

\section{ANAHTAR KELIMELER}

Biyomateryal, makaslama bağlanma dayanımı, vital pulpa tedavisi

Pulpa tedavilerinin başlıca amacı diş ve çevre destek dokuların sağlığını ve bütünlüğünü korumaktır. ${ }^{1}$ Vital pulpa tedavisi, geri dönüşümlü pulpa yaralanmalarında pulpanın vitalitesini korumak ve fonksiyonunu sağlamak amacıyla uygulanan koruyucu bir pulpa tedavisidir. ${ }^{2}$

\section{ABSTRACT}

Evaluation of bond strength of restorative materials to calcium silicate-based biomaterials in vital pulp treatment

Background: The purpose of this study was to provide a comparative evaluation of the shear bond strengths of calcium silicate based biomaterials used in vital pulp treatment to resin modified glass ionomer cement and composite resin.

Methods: 78 acrylic blocks with a hole measuring $4 \mathrm{~mm}$ diameter and $2 \mathrm{~mm}$ height were prepared. Calcium silicate based biomaterials (ProRoot MTA, BioAggregate, Biodentine) were prepared in line with the manufacturers' instructions, inserted into hole and waited the recommended time for the setting. The biomaterials specimens were divided into resin modified glass ionomer cement and composite resin. After adhesive procedures, restorative materials were applied over the biomaterials with the help of cylindrical mold $(2 \mathrm{~mm}$ in diameter and $2 \mathrm{~mm}$ in height). All specimens were stored at $37^{\circ} \mathrm{C}$ for $24 \mathrm{~h}$ and shear bond strength was then measured by universal testing machine. Data were analyzed using one-way ANOVA and Tukey tests.

Results: The shear bond strength value of the composite resin was found to be higher than that of the resin modified glass ionomer in all biomaterials (ProRoot MTA, BioAggregate and Biodentine). When biomaterials were compared, it was found that both resin-modified glass ionomer cement and composite resin bond strength of Biodentine were significantly higher than ProRoot MTA and BioAggregate $(p<0.05)$.

Conclusion: In conclusion, composite resin could be preferred as a restorative material upon the calcium silicate-based biomaterials used in vital pulp treatment. In addition, biodentine may be a good alternative to MTA and BioAggregate because it exhibits both better binding strength values, shorter curing times, easier manipulation and lower cost.

\section{KEYWORDS}

Biomaterial, shear bond strength, vital pulp treatment

Vital pulpa tedavisinde lokal irritanlar uzaklaştırıldıktan sonra pulpa üzerine koruyucu bir materyal yerleştirilmektedir. ${ }^{2}$ Pulpa üzerine yerleştirilecek olan materyal, pulpanın vitalitesini sürdürebilecek, bakteriyel sızıntıyı önleyebilecek,

\footnotetext{
${ }^{*}$ Bu çalışma, Eskişehir Osmangazi Üniversitesi Bilimsel Araştırma Projeleri Komisyonu tarafindan 2017-45A201 proje numarası ile desteklenmiştir.

${ }^{\alpha}$ Eskişehir Osmangazi Üniversitesi Diş Hekimliği Fakültesi Çocuk Diş Hekimliği Anabilim Dall, Eskişehir
} 
restorasyonun yerleştirilmesi ve fonksiyon sırasındaki kuvvetlere dirençli olabilecek ve dentin köprüsü oluşumunu sağlayabilecek özelliklere sahip biyouyumlu bir materyal olmalıdır. ${ }^{3-6}$

Kalsiyum hidroksit, vital pulpa tedavilerinde yaygın olarak kullanılmaktadır. ${ }^{7,8}$ İçeriğindeki hidroksil iyonlarından dolayı sahip olduğu yüksek alkalen pH'sı pulpada bir yaralanma meydana getirmekte, yüzeyde ise koagülasyon nekrozu ve orta derece enflamasyon oluşmaktadır. Bu nekroz alan, distorfik kalsifikasyonla yerini tamir dentinine bırakarak dentin köprüsü oluşumunu sağlamaktadır. $^{9}$ Ancak kalsiyum hidroksit kullanılan vital pulpa tedavilerinde oluşan distrofik kalsifikasyonların, pulpa kanlanmasını bozarak pulpa nekrozuna sebep olabileceğini gösteren çalışmalar da mevcuttur. ${ }^{10,11}$ Ayrıca kalsiyum hidroksit, dentine bağlantısının zayıf olması, mikrosızıntıya karşı uzun süren dayanıklıık gösterememesi, nem varlığında çözünmesi ve dentin köprüsünde poröziteye (tünel defektleri) neden olmasından dolayı vital pulpa tedavilerinde başarısızlığa neden olmaktadır. ${ }^{8,12}$ Bu nedenlerden dolayı günümüzde vital pulpa tedavilerinde Mineral Trioksit Aggregate (MTA), Biodentine, BioAggregate gibi hidratasyonu kalsiyum hidroksit formasyonu ile sonuçlanan ${ }^{13}$ kalsiyum silikat içerikli biyoseramik materyaller daha popüler hale gelmiştir. ${ }^{14-16}$

Vital pulpa tedavisinin başarısı için iyi bir örtücülük sağlanması ve bunun sürdürülmesi için tedaviden hemen sonra daimi restorasyonun yerleştirilmesi gerekmektedir. ${ }^{17}$ Bunun yanısıra bakteriyel mikrosızıntının azaltımasında, vital pulpa tedavisinin uzun dönem başarısında, pulpa kaplama materyali ile restoratif materyal arasındaki bağlanma kuvvetinin de yüksek olması gerekmektedir. ${ }^{18}$ Bu nedenle, bu araştırmada, vital pulpa tedavilerinde kullanılan kalsiyum silikat içerikli biyomateryallerin farklı restoratif materyallere makaslama bağlanma dayanımlarının karşılaştırmalı olarak değerlendirilmesi amaçlandı. Araştırmamızın hipotezi; Her bir biyomateryalin, rezin modifiye cam iyonomer siman ve kompozit rezinlere bağlanma dayanımları farklıdır.

\section{GEREÇ VE YÖNTEM}

\section{Çalışmada Kullanılan Materyaller}

Araştırmamızda, 3 farklı biyomateryal (ProRoot MTA, BioAggregate ve Biodentine), 2 farklı restoratif materyal (rezin modifiye cam iyonomer siman ve kompozit rezin) ve bir adet self-etch adeziv materyal kullanıldı (Tablo 1 ).
Tablo 1.

\section{Araştırmada kullanılan materyaller}

\begin{tabular}{|c|c|c|c|c|}
\hline Materyal & Tipi & İçeriği & $\begin{array}{l}\text { Lot } \\
\text { Numarası }\end{array}$ & $\begin{array}{l}\text { Üretici } \\
\text { Firma }\end{array}$ \\
\hline ProRoot MTA & $\begin{array}{l}\text { Kök kanal } \\
\text { tamir } \\
\text { materyali }\end{array}$ & $\begin{array}{l}\text { Trikalsiyum } \\
\text { silikat, dikalsiyum } \\
\text { silikat, trikalsiyum } \\
\text { aluminat, } \\
\text { kalsiyum sülfat } \\
\text { dihidrat, bizmut } \\
\text { oksit }\end{array}$ & 0000154618 & $\begin{array}{l}\text { Dentsply, } \\
\text { Tulsa } \\
\text { Dental, } \\
\text { OK, USA }\end{array}$ \\
\hline BioAggregate & $\begin{array}{l}\text { Kök kanal } \\
\text { tamir dolgu } \\
\text { materyali }\end{array}$ & $\begin{array}{l}\text { Trikalsiyum } \\
\text { silikat, dikalsiyum } \\
\text { silikat, tantalyum } \\
\text { pentoksit, } \\
\text { kalsiyum fosfat } \\
\text { monobazik, amorf } \\
\text { silikon oksit }\end{array}$ & 1201BA & $\begin{array}{l}\text { Innovative } \\
\text { BioCerami } \\
x, \\
\text { Vancouver, } \\
\text { Canada }\end{array}$ \\
\hline Biodentine & $\begin{array}{l}\text { Biyoaktif } \\
\text { dentin } \\
\text { materyali } \\
\text { (Trikalsiyu } \\
\text { m silikat } \\
\text { siman) }\end{array}$ & $\begin{array}{l}\text { Tozu: Trikalsiyum } \\
\text { silikat, dikalsiyum } \\
\text { silikat, kalsiyum } \\
\text { karbonat ve oksit, } \\
\text { zirkonyum oksit, } \\
\text { demir oksit } \\
\text { Likiti: kalsiyum } \\
\text { klorit, suda } \\
\text { çözünebilir } \\
\text { polimer }\end{array}$ & B20212 & $\begin{array}{l}\text { Septodont, } \\
\text { Saint Maur } \\
\text { des } \\
\text { Fossés, } \\
\text { France }\end{array}$ \\
\hline Clearfil SE & $\begin{array}{l}\text { Self-etch } \\
\text { adeziv }\end{array}$ & $\begin{array}{l}\text { Primer: 10-MDP, } \\
\text { HEMA, hidrofilik } \\
\text { dimetakrilat, CQ, } \\
\text { N,N-dietanol-p- } \\
\text { tolidin, su } \\
\text { Adheziv: 10-MDP, } \\
\text { HEMA, Bis-GMA, } \\
\text { hidrofobik } \\
\text { dimetakrilat, CQ, } \\
\text { N-dietanol-p- } \\
\text { tolidin, silika }\end{array}$ & 000242 & $\begin{array}{l}\text { Kuraray } \\
\text { Corp., } \\
\text { Osaka, } \\
\text { Japan }\end{array}$ \\
\hline Fuji II LC & $\begin{array}{l}\text { Rezin } \\
\text { modifiye } \\
\text { cam } \\
\text { iyonomer } \\
\text { siman }\end{array}$ & $\begin{array}{l}\text { Tozu: } \\
\text { Floroalumina } \\
\text { silikat cam } \\
\text { Likiti: Poliakrilik } \\
\text { asit, HEMA, } \\
\text { dimetakrilat, CQ, } \\
\text { distile su }\end{array}$ & 1606061 & $\begin{array}{l}\text { GC Corp, } \\
\text { Tokyo, } \\
\text { Japan }\end{array}$ \\
\hline Filtek Z550 & $\begin{array}{l}\text { Nano hibrit } \\
\text { universal } \\
\text { kompozit } \\
\text { rezin }\end{array}$ & $\begin{array}{l}\text { Silanlanmış } \\
\text { seramik, } \\
\text { silanlanmış silika, } \\
\text { UDMA, Bis-GMA, } \\
\text { TEGDMA, } \\
\text { Bisfenol A } \\
\text { polietilen glikol } \\
\text { dieter dimetakrilat }\end{array}$ & N917719 & $\begin{array}{l}\text { 3M/ESPE, } \\
\text { St. Paul, } \\
\text { MN, USA }\end{array}$ \\
\hline
\end{tabular}

Bis-GMA: Bisfenol A-Glisidil Dimetakrilat; CQ: Kamforokinon; HEMA: Hidroksietil Metakrilat; MDP: Metakriloiloksidodesil Dihidrojen Fosfat; TEGDMA: Trietilen Glikol Dimetakrilat; UDMA: Üretan Dimetakrilat.

\section{Örneklerin hazırlanması}

Bağlanma dayanım testi için 4 milimetre $(\mathrm{mm})$ çapında ve $2 \mathrm{~mm}$ derinlikte silindirik boşlukları bulunan 78 adet akrilik blok hazırlandı. Her bir biyomateryalden 26 adet olacak şekilde, üretici firmaların talimatları doğrultusunda hazırlanan biyomateryaller (ProRoot MTA, BioAggregate, Biodentine) akrilik bloklardaki boşluklara yerleştirildi. Akrilik blok seviyesi ile aynı seviyede olacak şekilde biyomateryallerin fazlası yüzeyden uzaklaştırıldıktan sonra üzerlerine nemli pamuk pelet konuldu ve geçici dolgu maddesi (Cavit, 3M ESPE, America Inc., Norristown, PA, 
USA) ile kapatıldı. Ardından ProRoot MTA ve BioAggregate örnekleri 4 saat, Biodentine örnekleri ise 12 dakika $37^{\circ} \mathrm{C}$ lik etüvde (Nüve ES 252, Nüve Sanayi Malzemeleri İmalat ve Ticaret A.Ş., Ankara, Türkiye) distile su içerisinde bekletildi. Etüvden çıkarılan örneklerin üzerindeki geçici dolgu maddesi ve pamuk peletler kaldırılı. Ardından biyomateryallerin yüzey polisajları alüminyum oksit diskler (Soflex; 3M/ESPE, St. Paul, MN, USA) kullanılarak gerçekleştirildi.

Biyomateryallerin üzerine uygulanacak restoratif materyalleri yerleştirmek için polietilenden hazırlanmış 2 mm çapında ve $2 \mathrm{~mm}$ yüksekliğinde silindirik bir kalıp kullanıldı. Her bir biyomateryal örnekleri uygulanacak restoratif materyale göre her grupta 13 adet örnek olacak şekilde rastgele 2 gruba ayrıldı;

Biyomateryal + Rezin Modifiye Cam İyonomer Siman: Biyomateryallerin üzerine üretici firmanın önerileri doğrultusunda hazırlanan rezin modifiye cam iyonomer siman (Fuji II LC) uygulandı ve 20 sn LED ışık cihazı ile polimerize edildi.

Biyomateryal + Kompozit Rezin: Biyomateryallerin üzerine Clearfil SE bond üretici firma talimatına göre uygulandıktan sonra kompozit rezin (Filtek Z550) yerleştirildi ve 20 sn LED ışık cihazı ile polimerize edildi.

\section{Makaslama bağlanma dayanımının değerlendirilmesi}

Tüm örnekler 24 saat $37^{\circ} \mathrm{C}$ 'lik etüvde distile su içerisinde bekletildikten sonra, makaslama bağlanma dayanım değerlerini ölçmek için universal test cihazına (MOD Dental MIC-101, Esetron Smart Robotechnologies, Ankara, Türkiye) sabitlendi. Ardından $1 \mathrm{~mm} /$ dakika hız olacak şekilde kopma meydana gelene kadar bağlanma alanının uzun eksenine paralel olacak şekilde kuvvet uygulanarak her bir örneğin kopma değeri Newton cinsinden ölçüldü. Daha sonra her bir örnek için kopma değeri, kuvvetin yüzey alanına bölümü sonucu hesaplanarak MPa cinsinden kaydedildi.

Koparılan örnekler stereomikroskop (Leica MZ16, Leica Microsystems Ltd., Heerbrugg, Germany) altında x40 büyütmede değerlendirilerek kırılma tiplerine göre aşağıdaki gibi tanımlandı:

Adeziv: Biyomateryal ve restoratif materyal arasında, Koheziv: Biyomateryal veya restoratif materyal içinde, Karışık (miks): koheziv ve adheziv kopmanın birarada olmasıdır.

\section{İstatistiksel değerlendirme}

Araştırmamızda elde edilen verilerin istatistiksel analizleri "Statistical Package for the Social Sciences" yazılımı (SPSS 21 for Windows, SPSS Inc., Chicago, Illinois, USA) kullanılarak gerçekleştirildi.
Elde edilen verilerin istatistiksel olarak değerlendirilmesinde tek yönlü varyans analizi (Oneway-ANOVA) kullanıldı. Eğer farklılık mevcut ise, hangi gruplar arasında farklılık olduğunu tespit etmek için ise Tukey testi uygulandı.

Analizlerde istatistiksel anlamlılık düzeyi $p<0.05$ olarak kabul edildi.

\section{BULGULAR}

ProRoot MTA, BioAggregate ve Biodentine örneklerinin ortalama makaslama bağlanma dayanımı değerleri Tablo 2'de gösterildi.

Tablo 2.

ProRoot MTA, BioAggregate ve Biodentine örneklerinin ortalama makaslama bağlanma dayanımı değerleri

\begin{tabular}{|c|c|c|}
\hline \multirow[b]{2}{*}{ Biyomateryaller } & \multicolumn{2}{|c|}{ Ortalama \pm Standart Sapma (MPa } \\
\hline & $\begin{array}{l}\text { Rezin modifiye } \\
\text { cam iyonomer }\end{array}$ & Kompozit rezin \\
\hline ProRoot MTA & $6.22 \pm 0.84^{2, b}$ & $7.76 \pm 1.68^{2, a}$ \\
\hline BioAggregate & $6.27 \pm 0.55^{2, a}$ & $7.12 \pm 0.63^{2, a}$ \\
\hline Biodentine & $7.58 \pm 1.30^{1, b}$ & $10.10 \pm 1.94^{1, a}$ \\
\hline
\end{tabular}

ProRoot MTA ve Biodentine örneklerinde kompozit rezin grubu rezin modifiye cam iyonomer siman grubundan anlamlı olarak daha yüksek ortalama makaslama bağlanma dayanım değeri sergiledi $(p<0.05)$ (Tablo 2). BioAggregate örneklerinde ise rezin modifiye cam iyonomer siman ve kompozit rezin grupları arasında ise istatistiksel olarak anlamlı bir farklılık gözlenmese de kompozit rezinin daha yüksek bağlanma dayanım değerine sahip olduğu saptandı ( $p>0.05)$ (Tablo 2).

Biyomateryaller karşılaştırıldığında, hem rezin modifiye cam iyonomer siman hem de kompozit rezin gruplarında Biodentine örneklerinin ortalama bağlanma dayanımı değerinin, ProRoot MTA ve BioAggregate'ye göre daha yüksek olduğu gözlendi $(p<0.05)$ (Tablo 2)

Biyomateryal-restoratif materyal arasındaki kırılma tipleri incelendiğinde, tüm gruplarda en fazla adeziv başarısızlık gözlendi (Tablo 3). 
Tablo 3.

\section{Biyomateryal-restoratif materyal arasında gözlenen kırılma tipleri}

\begin{tabular}{lcccc|}
\hline \multirow{2}{*}{ Biyomateryaller } & \multicolumn{3}{c}{ Kırılma Tipleri } \\
\cline { 2 - 4 } & Adeziv & Koheziv & Karışık \\
\hline ProRoot MTA & 14 & 8 & 4 \\
\hline BioAggregate & 13 & 5 & 8 \\
\hline Biodentine & 12 & 7 & 7
\end{tabular}

\section{TARTIŞMA}

Başarılı bir vital pulpa tedavisinin, mevcut odontoblastlardaki hasarı ortadan kaldırmak ve yeni odontoblastların farklılaşmasını sağlamak gibi iki ana stratejisi vardır. ${ }^{19}$ Tedavinin başarısında, pulpa hasarının derecesi, uygulanan kaplama materyali ve bakteriyel sızıntının etkisi önemlidir. ${ }^{20}$ Vital pulpa tedavisinde kullanılacak materyalin, bakterileri öldürme, mineralizasyonu sağlama ve iyi bir bakteriyel örtücülük oluşturma özelliğine sahip olması gerekmektedir. İdeal pulpa kaplama materyali, uzun süreli bakteriyel sızıntıya karşı koyabilmeli ve kalan pulpa dokusunu sağlıklı bir duruma döndürerek dentin oluşumunu teşvik etmelidir. ${ }^{21}$

Vital pulpa tedavisinde yaygın kullanılan materyal kalsiyum hidroksitin ${ }^{7,8}$ dezavantajları nedeniyle $8,10-12$ ideal bir materyal olmadığı bildirilmektedir. ${ }^{8,10,12} \mathrm{Bu}$ nedenle günümüzde kalsiyum silikat içerikli biyomateryallerin kullanımı daha popüler hale gelmiştir. ${ }^{14-16}$

Diş hekimliği alanında kullanılan ilk kalsiyum silikat içerikli siman olan $\mathrm{MTA}^{22}$, mükemmel sızdırmazlık özelliğine sahip, sert doku oluşumunu uyaran, yüksek alkalen yapıda, antibakteriyel etkinlik ve düşük çözünürlük gösteren biyouyumlu bir materyaldir. ${ }^{23-25}$ MTA'nın yüksek örtücülük kapasitesi vital pulpa tedavilerinin başarısında önemli bir rol oynamaktadır. ${ }^{26}$ Ancak, MTA'nın sertleşme süresinin uzun olması, uygulanmasının zor olması, maliyetinin yüksek olması ve renklenmeye neden olması gibi dezavantajları bulunmaktadır. ${ }^{27}$ Ayrıca materyalin henüz herhangi bir çözücüsünün olmaması ${ }^{28}$, uygulandıktan ve sertleştikten sonra uzaklaştırımasının zor olması ${ }^{29}$, rezin restorasyonların bağlantı kuvvetini artırmak için uygulanan asitleme işleminin MTA'nın bağlanma kuvvetini düşürmesi ${ }^{30}$ MTA'ya alternatif materyal arayışlarının sürmesine neden olmuştur.

Kalsiyum-silikat-fosfat içerikli bir biyoseramik olan BioAggregate ${ }^{31}$, MTA'nın modifiye edilmiş halidir. ${ }^{32}$ MTA'dan farklı olarak BioAggregate yapısında alüminyum bileşenleri içermemektedir. ${ }^{32,33}$ MTA'nın radyoopak özelliğini bizmut oksit sağlarken, BioAggregate'de bizmut oksit yerine tantalyum oksit bulunmaktadır. ${ }^{32,34}$

Biodentine ise özellikle "biyoaktif dentin muadili" olarak piyasaya sürülen ve pulpa kaplamasında kullanılan, hızlı sertleşen trikalsiyum silikat içerikli bir simandır. ${ }^{35}$ Kapsül şeklinde olup sertleşme süresi diğer kalsiyum silikat içerikli simanlara göre daha az olan (12 dakika) ${ }^{15,35,36}$ ve yüksek biyouyumluluğa sahip olan Biodentine ${ }^{36}$ çocuk diş hekimliği gibi özellikle tek seansta tedavinin gerekli olduğu durumlarda önemli bir avantaj sağlamaktadır. ${ }^{15}$

Vital pulpa tedavilerinde pulpa kaplama materyali ile restoratif materyal arasındaki bağlanma oldukça önemlidir. Eğer iyi bir örtücülük sağlanamazsa bakteriler pulpaya nüfuz olarak tedavinin başarısız olmasına neden olabilir. ${ }^{18} \mathrm{Bu}$ yüzden kalsiyum silikat içerikli simanların restoratif materyallere bağlanma dayanımı önemli bir klinik faktördür. ${ }^{37}$ Pulpa kaplamasından sonra dişe uygun bir restoratif materyal seçiminde ve özellikle estetiğin önemli olduğu bölgelerde kompozit rezinler ilk seçenektir. Ancak minede yeterli preparasyonun yapılamadığı vakalarda rezin modifiye cam iyonomer simanlar da tercih edilebilmektedir. ${ }^{38}$ Ayrıca her iki restoratif materyal yerleştirilmesi sırasında düşük kondenzasyon kuvveti gerektirdiğinden pulpa kaplama materyalinin üzerine uygulanacak uygun restoratif materyallerdir. ${ }^{39,40}$

Kalsiyum silikat içerikli materyallerin makaslama bağlanma dayanımı ile ilgili literatür incelendiğinde, çalışmaların büyük kısmının MTA ve Biodentine hakkında olduğu ${ }^{17,38,40-46}$ ve BioAggregate hakkında ise sınırlı sayıda çalışma olduğu tespit edildi. ${ }^{47,48}$ Ayrıca yapılan çalışmaların genellikle kalsiyum silikat içerikli materyallerin kompozit rezine bağlanma dayanımına odaklandığı ${ }^{17,37-45,47,49-51}$ ve rezin modifiye cam iyonomer simana bağlanma dayanımı hakkında ise daha az sayıda çalışma olduğu gözlendi. ${ }^{38,40,46}$ Bu nedenlerden dolayı, bu araştırmada, vital pulpa tedavilerinde kullanılan kalsiyum silikat içerikli biyomateryaller olan MTA, BioAggregate ve Biodentine'in rezin modifiye cam iyonomer siman ve kompozit rezine olan makaslama bağlanma dayanımlarııı karşılaştırmalı olarak değerlendirilmesi amaçlandı.

Materyallerin adeziv özelliklerinin değerlendirilmesinde en yaygın kullanılan yöntem, bağlanma dayanımlarının değerlendirilmesidir. ${ }^{51}$ Materyallerin bağlanma dayanımı hakkındaki in vitro testler araştırıcılara objektif bilgiler sunmaktadır. ${ }^{52}$ Ajami ve ark. ${ }^{50}$ MTA'nın kırılgan bir materyal olduğunu, bu nedenle gerilim bağlanma dayanımı testi için uygun bir materyal olmadığını rapor etmişlerdir. Bu nedenlerden dolayı araştırmamızda, kalsiyum silikat içerikli biyomateryallerin farklı restoratif materyallere adezyonunu değerlendirmede makaslama bağlanma dayanım testi kullanıldı. 
ProRoot MTA'nın kompozit rezine bağlanma dayanımı Savadi Oskoee ve ark. ${ }^{17}$ tarafından 48 saat sonunda $3.08 \mathrm{MPa}$, Jaberi-Ansari ve ark. ${ }^{39}$ tarafından $4.52 \mathrm{MPa}$, Alzraikat ve ark. ${ }^{53}$ tarafından 4.61 MPa olarak saptanırken, Cantekin \& Avcl ${ }^{49} 96$ saat sonra 8.5 ve $8.9 \mathrm{MPa}$ olarak saptamışlardır. Shin ve ark. ${ }^{42}$, sertleşme süresi olarak bir hafta bekletilen ProRoot MTA'nın, Clearfil SE Bond kullanılarak kompozit rezine bağlanma dayanımını değerlendirdikleri çalışmalarında, ortalama bağlanma dayanımın $5.29 \mathrm{MPa}$ olduğunu bildirmişlerdir. Araştırmamızda ProRoot MTA'nın kompozit rezine makaslama bağlanma dayanım değeri Cantekin \& Avci $^{49}$ ve Cantekin'in ${ }^{54}$ yaptığ çalışmalara yakın değerlerde bulunmuştur. Elde edilen araştıma sonuçlarımıza göre ProRoot MTA'nın rezin modifiye cam iyonomer simanlara bağlanma dayanım değerinin (6.22 MPa) ise diğer çalışmalardan ${ }^{38,40,46}$ (2.25-3.24 MPa arasında) daha yüksek olduğu saptandı. Çalışmalarda farklı bağlanma dayanım değerlerinin gözlenmesinin nedeni, kullanılan yöntem, adezivin tipi, içerdiği asidik monomerin pH'sı, solven tipi, doldurucu içeriği ve MTA'nın sertleşme süresi olarak farklı zamanların kullanılması ile ilişkili olabilir. ${ }^{55}$ Diğer çalışmalara ${ }^{38,40,46}$ benzer şekilde araştırmamızda da rezin modifiye cam iyonomer simana bağlanma dayanımının, kompozit rezinden anlamlı olarak daha düşük olduğu gözlendi $(p<0.05)$. Bu çerçevede ProRoot MTA için araştırma hipotezimiz kabul edildi. ProRoot MTA'nın kompozit rezinde makaslama bağlanma dayanımının daha yüksek olmasının, kompozit rezinde kullanılan adeziv ajandan dolayı olabileceğini düşünmekteyiz. Araştırmamızda da kullandığımız Clearfil SE adeziv 10-MDP fonksiyonel monomer içermektedir. Bu momomer, kalsiyum silikat içerikli materyallerdeki kalsiyum ile kimyasal olarak bağlandığından mikromekanik bağlanmaya ilaveten kimyasal adezyonu da sağlamaktadır. ${ }^{56}$

Literatürde BioAggregate'in restoratif materyallere makaslama bağlanma dayanımı ile ilgili çalışmalar incelendiğinde yalnızca Yesilyurt ve ark.'nın ${ }^{48}$ çalışmasının olduğu tespit edildi. Bu çalışmada araştırmacılar 24 ve 72 saatlik sertleşme süresinden sonra BioAggregate'in farklı akışkan kompozit rezinlere bağlanma etkinliğini değerlendirmişlerdir. Çalışma sonucunda, BioAggregate'in 24 saatlik sertleşme süreci sonucunda Clearfil SE kullanılarak akışkan kompozit rezine makaslama bağlanma dayanımının ortalama $3.31 \mathrm{MPa}$ olduğunu bildirilmişlerdir. Araştırmamızda ise BioAggregate'in kompozit rezine makaslama bağlanma dayanımının Yesilyurt ve ark.'nın ${ }^{48}$ çalışmalarından daha yüksek olduğu bulundu (7.12 MPa). Ayrıca araştırmamızda BioAggregate'in rezin modifiye cam iyonomer siman ve kompozit rezine bağlanma dayanımı arasında istatistiksel olarak anlamlı bir farklılık bulunamadığından $(p>0.05)$, BioAggregate için hipotez reddedildi. Literatürde BioAggregate'in rezin modifiye cam iyonomer simana makaslama bağlanma dayanımı hakkında herhangi bir çalışma olmaması nedeni ile bu bulgumuz diğer araştırmalar ile karşılaştırılamadı.

Çolak ve ark. ${ }^{44}$ Biodentine'nin 9 dakika ve 48 saat sertleşmesinden sonra farklı adezivlerle kompozit rezine makaslama bağlanma dayanımını değerlendikleri çalışmalarında, sertleşme zamanının bir öneminin olmadığını göstermişlerdir. Ancak her iki zamanda da iki farklı self-etch adeziv karşılaştırıldığında 10-MDP içeren Clearfil S3 (9 dakikada 13.32 MPa, 48 saatte $15.09 \mathrm{MPa}$ ), Adper Prompt L Pop'tan (9 dakikada 9.82 MPa, 48 saatte $9.82 \mathrm{MPa}$ ) daha yüksek bağlanma dayanımı sergilediğini belirtmişlerdir. Benzer şekilde Odabaş ve ark.'nın ${ }^{45}$ yaptığı çalışma sonucunda da, farklı sertleşme süresinin (12 dakika ve 24 saat) Biodentine'nin bağlanma dayanımını etkilemediği ve iki aşamalı self-etch adeziv olan Clearfil SE Bond'un en yüksek bağlanma dayanımına sahip olduğunu bildirilmiştir (12 dakikada 16.90 MPa, 24 saatte 19.559 MPa). Biodentine'nin kompozit rezine bağlanma dayanımı hakkında yapılan çalışmalarda 1.69-17.7 MPa arasında değişen değerlere sahip olduğu bulunmuştur. ${ }^{37,43,46,49}$ Araştırmamızda Biodentine örneklerinde en yüksek ortalama makaslama bağlanma dayanım değeri kompozit rezin grubunda (10.10 MPa) gözlendi. Yapılan diğer çalışmalarla ${ }^{46,49}$ uyumlu olarak araştırmamızda da Biodentine'nin kompozit rezine bağlanma dayanımının rezin modifiye cam iyonomer simandan daha yüksek olduğu saptandı. Dolayısıyla Biodentine için araştırma hipotezimiz kabul edildi.

Kalsiyum silikat içerikli biyomateryallerin bağlanma dayanımlarının karşılaştıııldığı çalışmalar incelendiğinde, MTA ve Biodentine'nin bağlanma dayanımın değerlendirildiği çalışma sonuçlarının çelişkili olduğu görülmektedir. Tulumbaci ve ark.'nın ${ }^{46}$ ProRoot MTA ve Biodentine'nin farklı restoratif materyallere makaslama bağlanma dayanımını karşılaştırdıkları çalışmanın sonucuna göre, ProRoot MTA kompozit rezine Biodentine'den daha yüksek bağlanma dayanımı gösterirken, rezin modifiye cam iyonomer simana bağlanmada ProRoot MTA ve Biodentine arasında anlamlı bir farklılık gözlenmemiştir. Araştırmamızda ProRoot MTA, BioAggregate ve Biodentine karşılaştırıldığında hem rezin modifiye cam iyonomer siman hem de kompozit rezin gruplarında Biodentine'nin makaslama bağlanma dayanımının ProRoot MTA ve BioAggregate'den daha yüksek olduğu saptandı.

Biyomateryal-restoratif materyal arasındaki kırılma tipleri incelendiğinde, yapılan diğer çalışmalar ${ }^{40,54,57}$ ile uyumlu olarak tüm gruplarda daha çok adeziv başarısızlık gözlendi. Bu da biyomateryal ile restoratif materyaller arasında güçlü bir bağlanma olmadığını göstermektedir. Alzkariat ve ark. ${ }^{53}$ MTA'nın yapısındaki su içeriğinin selftetch adezivlerin polimerizasyonuna etki edebileceğini ve 
MTA-adeziv arasındaki bağlantı kuvvetini düşürebileceğini ifade etmişlerdir.

\section{SONUÇ}

Araştırmamızdan elde ettiğimiz bulgular ışığında, vital pulpa tedavilerinde kullanılan kalsiyum silikat içerikli biyomateryallerin üzerine kompozit rezinin final restorasyon olarak kullanılmasının uygun olacağı kanısındayız. Ayrıca Biodentine'nin, hem bağlanma dayanımı açısından daha iyi değerler sergilemesi, hem de sertleşme süresinin daha kısa olması, manipülasyonunun daha kolay olması ve daha ucuz olması nedeniyle MTA ve BioAggregate'e iyi bir alternatif olabileceği görüşündeyiz. 


\section{KAYNAKLAR}

1. Guideline on pulp therapy for primary and immature permanent teeth. Pediatr Dent 2016; 38(6): 280-8.

2. Hargreaves KM, Cohen S, Berman LH. Cohen's pathways of the pulp. Baskı. St. Louis, Mo.: Mosby Elsevier; 2011.

3. Cohen BD, Combe EC. Development of new adhesive pulp capping materials. Dent Update 1994; 21(2): 57-62.

4. Modena KC, Casas-Apayco LC, Atta MT, Costa CA, Hebling J, Sipert CR, Navarro MF, Santos CF. Cytotoxicity and biocompatibility of direct and indirect pulp capping materials. J Appl Oral Sci 2009; 17(6): 544-54.

5. Queiroz AM, Assed S, Leonardo MR, Nelson-Filho $P$, Silva LA. Mta and calcium hydroxide for pulp capping. J Appl Oral Sci 2005; 13(2): 126-30.

6. Lee H, Shin Y, Kim SO, Lee HS, Choi HJ, Song JS. Comparative study of pulpal responses to pulpotomy with proroot mta, retromta, and theracal in dogs' teeth. J Endod 2015; 41 (8): 1317-24.

7. Hilley LCJ, McNally CK. Bioceramics in endodontics. Clin Update 2013; 35(4).

8. Zhu L, Yang J, Zhang J, Peng B. A comparative study of bioaggregate and proroot mta on adhesion, migration, and attachment of human dental pulp cells. J Endod 2014; 40(8): 1118-23.

9. Briso AL, Rahal V, Mestrener SR, Dezan Junior E. Biological response of pulps submitted to different capping materials. Braz Oral Res 2006; 20(3): 21925.

10.Fuks $A B$. Pulp therapy for the primary and young permanent dentitions. Dent Clin North Am 2000; 44(3): 571-96, vii.

11.Bakland LK. Revisiting traumatic pulpal exposure: Materials, management principles, and techniques. Dent Clin North Am 2009; 53(4): 661-73, v-vi.

12.Asgary S, Eghbal MJ, Parirokh $M$, Ghanavati $F$, Rahimi H. A comparative study of histologic response to different pulp capping materials and a novel endodontic cement. Oral Surg Oral Med Oral Pathol Oral Radiol Endod 2008; 106(4): 609-14.

13. Nekoofar MH, Davies TE, Stone D, Basturk FB, Dummer PM. Microstructure and chemical analysis of blood-contaminated mineral trioxide aggregate. Int Endod J 2011; 44(11): 1011-8.

14.Parirokh M, Torabinejad M, Dummer PMH. Mineral trioxide aggregate and other bioactive endodontic cements: An updated overview - part i: Vital pulp therapy. Int Endod J 2018; 51(2): 177-205.

15. Dawood AE, Parashos P, Wong RHK, Reynolds EC, Manton DJ. Calcium silicate-based cements: Composition, properties, and clinical applications. J Investig Clin Dent 2017; 8(2).
16. Cho SY, Seo DG, Lee SJ, Lee J, Lee SJ, Jung IY. Prognostic factors for clinical outcomes according to time after direct pulp capping. J Endod 2013; 39(3): 327-31.

17. Savadi Oskoee S, Bahari M, Kimyai S, Motahhari $\mathrm{P}$, Eghbal MJ, Asgary S. Shear bond strength of calcium enriched mixture cement and mineral trioxide aggregate to composite resin with two different adhesive systems. J Dent (Tehran) 2014; 11(6): 665-71.

18.Tziafas D, Smith AJ, Lesot $H$. Designing new treatment strategies in vital pulp therapy. J Dent 2000; 28(2): 77-92.

19.Zhang W, Yelick PC. Vital pulp therapy-current progress of dental pulp regeneration and revascularization. Int J Dent 2010; 2010856087.

20.Tziafas D, Belibasakis G, Veis A, Papadimitriou S. Dentin regeneration in vital pulp therapy: Design principles. Adv Dent Res 2001; 1596-100.

21. Witherspoon DE. Vital pulp therapy with new materials: New directions and treatment perspectives-permanent teeth. Journal of endodontics 2008; 34(7): S25-S8.

22. Jefferies $\mathrm{S}$. Bioactive and biomimetic restorative materials: A comprehensive review. Part ii. J Esthet Restor Dent 2014; 26(1): 27-39.

23.Asgary S, Kamrani FA, Taheri S. Evaluation of antimicrobial effect of mta, calcium hydroxide, and cem cement. Iranian endodontic journal 2007; 2(3): 105.

24.Camilleri J, Laurent P. Hydration of biodentine, theracal Ic, and a prototype tricalcium silicatebased dentin replacement material after pulp capping in entire tooth cultures. J Endod 2014; 40(11): 1846-54.

25.Tziafa C, Koliniotou-Koumpia E, Papadimitriou S, Tziafas D. Dentinogenic responses after direct pulp capping of miniature swine teeth with biodentine. J Endod 2014;40(12):1967-71.

26. Torabinejad M, Smith PW, Kettering JD, Pitt Ford TR. Comparative investigation of marginal adaptation of mineral trioxide aggregate and other commonly used root-end filling materials. J Endod 1995; 21(6): 295-9.

27. Makkar S, Vashisht R, Kalsi A, Gupta P. The effect of altered ph on push-out bond strength of biodentin, glass ionomer cement, mineral trioxide aggregate and theracal. Serbian Dental Journal 2015; 62(1): 7-13.

28. Macwan C, Deshpande A. Mineral trioxide aggregate (mta) in dentistry: A review of literature. Journal of Oral Research and Review 2014; 6(2): 71. 
29.Parirokh M, Torabinejad M. Mineral trioxide aggregate: A comprehensive literature review-part iii: Clinical applications, drawbacks, and mechanism of action. J Endod 2010;36(3):40013.

30. Kayahan MB, Nekoofar MH, McCann A, Sunay $H$, Kaptan RF, Meraji N, Dummer PM. Effect of acid etching procedures on the compressive strength of 4 calcium silicate-based endodontic cements. J Endod 2013;39(12):1646-8.

31. Yan $P$, Yuan Z, Jiang $H$, Peng B, Bian Z. Effect of bioaggregate on differentiation of human periodontal ligament fibroblasts. Int Endod $\mathrm{J}$ 2010;43(12):1116-21.

32. Park JW, Hong SH, Kim JH, Lee SJ, Shin SJ. Xray diffraction analysis of white proroot mta and diadent bioaggregate. Oral Surg Oral Med Oral Pathol Oral Radiol Endod 2010;109(1):155-8.

33. Diaroot bioaggregate. http://www.diadent.com. 2011.

34.Zhang $H$, Pappen FG, Haapasalo M. Dentin enhances the antibacterial effect of mineral trioxide aggregate and bioaggregate. J Endod 2009;35(2):221-4.

35.Biodentine scientific file active biosilicate technology, septodont. Saint-maur-des-fosse's cedex, france: R\&d department. 2010.

36. Camilleri J, Sorrentino F, Damidot D. Investigation of the hydration and bioactivity of radiopacified tricalcium silicate cement, biodentine and mta angelus. Dent Mater 2013;29(5):580-93.

37. Schmidt A, Schafer E, Dammaschke T. Shear bond strength of lining materials to calciumsilicate cements at different time intervals. J Adhes Dent 2017;19(2):129-35.

38. Ajami AA, Jafari Navimipour E, Savadi Oskoee S, Abed Kahnamoui M, Lotfi M, Daneshpooy M. Comparison of shear bond strength of resinmodified glass ionomer and composite resin to three pulp capping agents. J Dent Res Dent Clin Dent Prospects 2013;7(3):164-8.

39. Jaberi-Ansari Z, Mahdilou M, Ahmadyar M, Asgary S. Bond strength of composite resin to pulp capping biomaterials after application of three different bonding systems. J Dent Res Dent Clin Dent Prospects 2013;7(3):152-6.

40.Doozaneh M, Koohpeima F, Firouzmandi M, Abbassiyan F. Shear bond strength of selfadhering flowable composite and resin-modified glass ionomer to two pulp capping materials. Iran Endod J 2017;12(1):103-7.

41. Oskoee SS, Kimyai S, Bahari M, Motahari P, Eghbal MJ, Asgary S. Comparison of shear bond strength of calcium-enriched mixture cement and mineral trioxide aggregate to composite resin. $\mathrm{J}$ Contemp Dent Pract 2011; 12(6): 457-62.
42. Shin JH, Jang JH, Park SH, Kim E. Effect of mineral trioxide aggregate surface treatments on morphology and bond strength to composite resin. J Endod 2014; 40(8): 1210-6.

43. Altunsoy M, Tanriver M, Ok E, Kucukyilmaz E. Shear bond strength of a self-adhering flowable composite and a flowable base composite to mineral trioxide aggregate, calcium-enriched mixture cement, and biodentine. J Endod 2015; 41(10): 1691-5.

44. Colak H, Tokay U, Uzgur R, Uzgur Z, Ercan E, Hamidi MM. The effect of different adhesives and setting times on bond strength between biodentine and composite. J Appl Biomater Funct Mater 2016; 14(2): e217-22.

45. Odabas ME, Bani M, Tirali RE. Shear bond strengths of different adhesive systems to biodentine. ScientificWorldJournal 2013; 2013626103.

46. Tulumbaci F, Almaz ME, Arikan V, Mutluay MS. Shear bond strength of different restorative materials to mineral trioxide aggregate and biodentine. J Conserv Dent 2017; 20(5): 292-6.

47. Atabek D, Sillelioglu H, Olmez A. Bond strength of adhesive systems to mineral trioxide aggregate with different time intervals. J Endod 2012; 38(9): 1288-92.

48. Yesilyurt C, Ceyhanli KT, Kedici Alp C, Yildirim T, Tasdemir T. In vitro bonding effectiveness of new self-adhering flowable composite to calcium silicate-based material. Dent Mater J 2014; 33(3): 319-24.

49. Cantekin K, Avci S. Evaluation of shear bond strength of two resin-based composites and glass ionomer cement to pure tricalcium silicate-based cement (biodentine(r)). J Appl Oral Sci 2014; 22(4): 302-6.

50.Ajami AA, Bahari M, Hassanpour-Kashani A, AbedKahnamoui M, Savadi-Oskoee A, Azadi-Oskoee F. Shear bond strengths of composite resin and giomer to mineral trioxide aggregate at different time intervals. J Clin Exp Dent 2017; 9(7): e906-e11.

51.Tunc ES, Sonmez IS, Bayrak S, Egilmez T. The evaluation of bond strength of a composite and a compomer to white mineral trioxide aggregate with two different bonding systems. J Endod 2008; 34(5): 603-5.

52. Orhan DAI, Öz FT. Sık kullanılan bağlanma dayanım test metotları: Derleme çalışması. Turkiye Klinikleri Journal of Dental Sciences Special Topics 2011; 2(2): 31-40.

53. Alzraikat H, Taha NA, Qasrawi D, Burrow MF. Shear bond strength of a novel light cured calcium silicate based-cement to resin composite using different adhesive systems. Dent Mater J 2016; 35(6): 881-7. 
54. Cantekin K. Bond strength of different restorative materials to light-curable mineral trioxide aggregate. J Clin Pediatr Dent 2015; 39(2): 143-8.

55. Saghiri MA, Lotfi M, Saghiri AM, Vosoughhosseini S, Aeinehchi M, Ranjkesh B. Scanning electron micrograph and surface hardness of mineral trioxide aggregate in the presence of alkaline ph. J Endod 2009; 35(5): 706-10.

56. Yoshida Y, Nagakane K, Fukuda R, Nakayama Y, Okazaki M, Shintani H, Inoue S, Tagawa Y, Suzuki $\mathrm{K}$, De Munck J, Van Meerbeek B. Comparative study on adhesive performance of functional monomers. J Dent Res 2004; 83(6): 454-8.

57. Bayrak S, Tunc ES, Saroglu I, Egilmez T. Shear bond strengths of different adhesive systems to white mineral trioxide aggregate. Dent Mater $\mathrm{J}$ 2009; 28(1): 62-7.

Yazışma Adresi:

Arş. Gör. Hüseyin BiçER

Eskişehir Osmangazi Üniversitesi

Diş Hekimliği Fakültesi

Çocuk Diş Hekimliği Anabilim Dalı

Meşelik Kampüsü, Eskişehir, Türkiye

Tel : +90222 $2393750 / 1485$

Faks : +90 2222391273

e-Posta: h.bicer89@gmail.com 